\title{
Histórico da revista Estudos Bíblicos, de 1984 a 2020
}

\author{
History of the review Estudos Bíblicos, from 1984 to 2020 \\ Ludovico Garmus*
}

\footnotetext{
* Doutor em Teologia Bíblica (Pontifícia Universidade Antoniana de Roma/Jerusalém) e Mestre em Sagrada Escritura (Pontifício Instituto Bíblico de Roma).

Professor na Faculdade de Teologia do Instituto Teológico Franciscano de Petrópolis (1973-2020), Brasil. Professor convidado para a PósGraduação de Teologia da PUC-Rio (2006-2015), Brasil. Diretor e editor da revista $E s$ tudos Bíblicos do início até 2020. garmus@itf.org.br
}

Recebido em: 13/07/2020 Aprovado em: 25/04/2021

Licença Creative Commons CC BY 4.0 (c) $($ )

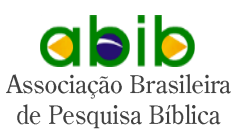

\begin{abstract}
Resumo
O artigo apresenta um histórico da revista Estudos Bíblicos, desde seu primeiro número, em 1984, até o número 143, em 2020. O período histórico analisado corresponde à fase em que a revista foi editada pela Editora Vozes, de Petrópolis, em forma impressa. Situa-se na nova fase da revista, que passa a ser publicada online, sob a responsabilidade da ABIB. O artigo começa pelas origens da Revista, a partir de um grupo ecumênico de exegetas, que se reunia nos inícios da década de 1980. Destaca o caráter ecumênico e pastoral que sempre pautou a publicação. Por algumas décadas a revista divulgou a produção literária de biblistas brasileiros e também estrangeiros, radicados no Brasil, sempre com foco na leitura popular da Bíblia.
\end{abstract}

Palavras-chave: Estudos Bíblicos. Leitura popular da Bíblia. Hermenêutica.

\begin{abstract}
The article presents a history of the review Estudos Bíblicos, from its first number in 1984 to number 143 in 2020. The historical period analyzed corresponds to the phase in which the review was published by Editora Vozes, from Petrópolis, in printed form. It is located in the new phase of the review, which is now published online, under the responsibility of the ABIB. The article begins with the origins of the review, from an ecumenical group of exegetes, who met in the early 1980s. It highlights the ecumenical and pastoral character that has always guided the publication. Over the course of a few decades, the review published the literary production of Brazilian and foreign scholars, always focusing on the popular reading of the Bible.
\end{abstract}

Keywords: Bible studies. Popular Bible reading. Hermeneutics.

\section{Introdução}

Este número da Revista Estudos Bíblicos marca uma nova fase em sua publicação. Após 36 anos de veiculação impressa, ininterrupta, pela Editora Vozes, ela passa agora a ser publicada online. 
Para comemorar essa passagem, o Conselho Editorial propôs um histórico da Revista Estudos Bíblicos, lembrando sua origem, características, estrutura, desenvolvimento e perspectivas de futuro que se apresentavam. Uma primeira versão desse histórico foi apresentada no II Congresso Bíblico da Associação Brasileira de Pesquisa Bíblica (ABIB), realizado em Goiânia/GO, em 20071.

Uma segunda versão atualizada da comunicação foi publicada para celebrar os 25 anos da Revista, e incluiu um índice bíblico analítico dos cem primeiros números de Estudos Bíblicos (GARMUS, 2008, p. 9-19). Julgamos oportuno reapresentar o texto, com algumas modificações e atualizações, sem o índice bíblico analítico dos cem primeiros números de Estudos Bíblicos.

\section{Origem da revista Estudos Bíblicos}

Nos inícios da década de 1980, um grupo ecumênico de exegetas começou a reunir-se com o propósito comum de iniciar uma leitura mais sistemática da Bíblia na ótica da opção preferencial pelos pobres. Os bispos da Igreja Católica da América Latina haviam realizado as assembleias de Medellín (1968) e de Puebla (1979), traçando linhas de ação pastoral comum dentro do espírito da Teologia da Libertação (TL) e da leitura contextualizada da Bíblia. A TL estava em franco desenvolvimento e já fazia a sua hermenêutica contextualizada da leitura bíblica. Nas Igrejas também se fazia a leitura da Bíblia a partir dos pobres. A Bíblia tornara-se um instrumento indispensável de evangelização e ação pastoral ${ }^{2}$. Faltava, porém, da parte dos exegetas brasileiros uma leitura mais sistemática da Bíblia nessa mesma opção.

Formou-se um grupo de exegetas convidados para estudar alguns textos de comum interesse. $\mathrm{O}$ grupo se propunha a fazer uma hermenêutica mais apropriada de leitura bíblica, partindo das realidades de conflito em que vivia o povo mais pobre, mas valendo-se do instrumental da exegese histórico-crítica. As reuniões anuais duravam quatro a cinco dias. Entre os primeiros participantes, que lideravam o grupo, estavam Milton Schwantes ${ }^{3}$, Gilberto Gorgulho ${ }^{4}$, Ana Flora Anderson, José Comblin 5 , Paulo Lockmann, Carlos Mesters e Tércio Machado Siqueira. Algumas reuniões foram feitas em Angra dos Reis, no Convento dos Carmelitas.

1 O histórico era uma comunicação publicada por Reimer e Silva (2008, p. 189-193).

2 Para aprofundar o crescente interesse pela leitura e estudo da Bíblia pode-se consultar: GIRALDI (2018); SILVA (1990, p. 117-137).

3 Milton Schwantes, falecido em 2012, foi homenageado no vol. 29, n. 114, abril/junho 2012: Textos bíblicos, frutos de experiências transformadoras e a memória de Milton Schwantes (FERREIRA, 2012). Milton Schwantes foi também um dos principais responsáveis pela criação da Revista de Interpretação Bíblica Latino-Americana (RIBLA), publicada pela Editora Vozes (1988-2008).

4 Gilberto Gorgulho, falecido em 2012, foi homenageado no vol. 31, n. 123, julho/setembro 2014 (SIQUEIRA; FRIZZO, 2014). Homenagem muito justa em reconhecimento pela liderança exercida na criação da revista Estudos Bíblicos, na publicação do Comentário Bíblico.

5 José Comblin, falecido em 2011, recebeu homenagem no vol. 30, n. 119, julho/setembro 2014: A esperança de um mundo novo. Estudos bíblicos em memória do profeta José Comblin (CORREIA JÚNIOR; OLIVA, 2014). 
O grupo era ecumênico, e enriquecido por professores biblistas das Faculdades de Teologia Católica, Luterana, Metodista, Presbiteriana e Batista. Reuniam-se a cada ano para estudar textos bíblicos, sempre na perspectiva de uma leitura da Bíblia a partir dos pobres. Numa destas reuniões, discutiu-se a necessidade de publicar o resultado desses estudos. As discussões resultaram em dois projetos ambiciosos: 1. Criar uma revista de caráter bíblico-pastoral; 2. Organizar e escrever um comentário bíblico, escrito por autores latino-americanos ou nela radicados ${ }^{6}$. Os dois projetos deviam orientar-se pelo estudo crítico das Sagradas Escrituras, tendo como pano de fundo a escandalosa desigualdade social, sofrida pelos mais pobres, e a diversidade ecumênica de nossas Igrejas. Os dois projetos visavam veicular uma leitura libertadora da Bíblia a partir dos pobres. Em resumo, estimular uma leitura da Palavra de Deus, já existente entre o povo, para torná-la uma boa-nova transformadora na vida cristã.

Numa reunião deste grupo realizada em Petrópolis foram discutidas duas opções: criar uma revista nova ou aproveitar a oferta do então redator da Revista Eclesiástica Brasileira/REB, Leonardo Boff. A REB durante vários anos publicou uma secção de caráter homilético-litúrgico, chamada "A Mesa da Palavra". Em 1983 estava sendo concluída a série de apêndices. Ficavam disponíveis as páginas da REB para novas iniciativas. Leonardo Boff, sabendo do desejo de se criar uma revista de caráter bíblico, ofereceu o espaço para a iniciativa deste grupo ecumênico de exegetas, que desejavam publicar seus estudos de caráter bíblico-pastoral. Portanto, inicialmente, não seria uma revista independente, mas um anexo da REB.

Assim, em 1984, no vol. 44, fascículo 173 da REB nasceu como apêndice o primeiro número de "Estudos Bíblicos", com 66 páginas. O título era: "A Bíblia como memória dos pobres". O editorial era assinado por Leonardo Boff e Ludovico Garmus, responsáveis pela nova série por parte da Editora Vozes. Os autores do primeiro número eram Carlos Mesters, Pablo Richard, Milton Schwantes e Alberto Antoniazzi $(\dagger$ 2004).

\title{
3 Características da publicação
}

O Editorial do primeiro número, assinado por Leonardo Boff e Ludovico Garmus (1984, p. 5-6), assim apresentava a nova série:

\begin{abstract}
Esta nova seção da Revista Eclesiástica Brasileira quer oferecer aos leitores subsídios relacionados com o uso e a interpretação da Bíblia na vida cristã. O título 'Estudos Bíblicos' não pretende levar a uma leitura desengajada da Bíblia, mas chamar atenção à seriedade com que deve ser tratada a Palavra de Deus, enquanto desafio para uma vida cristã mais engajada e consciente. O material contido nesta seção será tam-
\end{abstract}

6 O Comentário Bíblico foi publicado pela Editora Vozes, em coedição com a Imprensa Metodista e a Editora Sinodal. O primeiro volume é de Milton Schwantes. Ageu. Comentário Bíblico/AT. Petrópolis: Vozes; Imprensa Metodista; Editora Sinodal, 1986, 73p. O último volume publicado pela Editora Vozes foi escrito por Carlos Mesters e Francisco Orofino, intitulado Apocalipse de São João, em 2002. Entre 1985 e 2003, foram publicados 27 volumes do Comentário Bíblico, assumido depois pelas Edições Loyola (SP). Atualmente é publicado pela Fonte Editorial (SP). 
bém publicado em separatas, para leitores não-assinantes da REB. O caráter destes 'Estudos Bíblicos' será ecumênico. Reunirá contribuições de autores católicos, luteranos, anglicanos e metodistas, que à seriedade da exegese científica procuram aliar uma leitura comprometida com a realidade conflitiva da vida do homem de hoje. Querem ler a Bíblia a partir da vida e iluminá-la, por sua vez, com a Palavra de Deus. Portanto, não se dará atenção às diferenças eclesiais de interpretação, mas tentar-se-á unir os esforços de todos no sentido de tornar os venerandos textos da Bíblia contemporâneos ao nosso tempo e atuantes nas lutas de libertação do Povo de Deus.

Assim, desde o início definiu-se o tipo de leitura da Bíblia que se pretendia fazer: "uma leitura comprometida com a realidade conflitiva de hoje", mas num âmbito ecumênico. Os colaboradores, porém, não pretendiam representar as posições oficiais de suas respectivas Igrejas. Como a REB é uma publicação trimestral, a seção "Estudos Bíblicos" assumiu a mesma periodicidade, ou seja, quatro números por ano, uma publicação trimestral.

O n. 2 de Estudos Bíblicos, intitulado "Caminho de libertação", reúne artigos, sobretudo, de autores de São Paulo: Ana Flora Anderson, Gilberto Gorgulho, Tércio Machado Siqueira, Paulo Lockmann, José Comblin, Carlos Tosar, Domingos Zamagna e inclui também resenhas de alguns livros. O n. 3, "Atos dos Apóstolos: ontem e hoje" foi preparado por autores de Minas Gerais. O n. 4, "Profetas: ontem e hoje" foi elaborado por biblistas do Nordeste.

Os números normalmente recolhem contribuições apenas de autores brasileiros ou radicados no Brasil. Mas o n. 7, "Leitura da Bíblia a partir das condições reais da vida", apresenta artigos de Clodovis Boff, Norman K. Gottwald, Elsa Tamez e Pablo Richard.

Os primeiros dez números tiveram uma tiragem inicial de 3.000 exemplares e alguns números foram até reeditados. Depois, por várias razões, como a econômica (inflação) e o surgimento de outras revistas no mercado, houve um recuo acentuado no número de assinantes e na tiragem.

Até o n. 12 (1986), Estudos Bíblicos permaneceu como um anexo da Revista Eclesiástica Brasileira, mas publicado também em cadernos separados para os não assinantes da REB e comercializado nas livrarias como livro. A partir do n. 13, em 1987, a série "Estudos Bíblicos" deixou de ser um anexo da REB e passou a ser publicada em separado, podendo os números ser adquiridos por assinatura. Ganhou maturidade e alçou um voo independente.

Desde o início a série "Estudos Bíblicos" teve a periodicidade de uma revista e era considerada como tal, mesmo sem levar o título oficial de revista. Ao se tornar uma publicação independente da REB, a revista recebeu o apoio da Editora Imprensa Metodista de São Bernardo do Campo/SP e da Editora Sinodal, de São Leopoldo/RS, cujos logotipos eram estampados na capa dos cadernos. O apoio da Imprensa Metodista permaneceu até o n. 31 (1991), quando foi retirado, por razões administrativas. A Editora Sinodal continuou apoiando até o n. 71 (2001), quando a publicação deixava de ser uma série de cadernos, para tornar-se oficialmente uma revista. Somente a partir do n. 72 (2002) Estudos Bíblicos foi registrada oficialmente como revista, com ISSN próprio. 


\section{Estrutura e desenvolvimento da revista}

Estudos Bíblicos tinha um Redator ou Editor responsável, representando a Editora Vozes, editora que se propôs a imprimir e comercializar a revista. Possuía um Conselho Editorial, composto por representantes das Igrejas que apoiaram a publicação ${ }^{7}$. Mais tarde, com as exigências do MEC, os integrantes do Conselho Editorial passaram a ser professores de Teologia ou Ciências da Religião de diferentes Universidades ou Faculdades de Teologia particular onde lecionavam.

Além disso, cada número tinha um coordenador ou coordenadora responsável que, junto com os colaboradores e colaboradoras de sua região, propunha o tema a ser desenvolvido. Não havia um redator único para coordenar a revista, pois a redação era volante. Os números eram produzidos pelos colaboradores de várias regiões do país: Rio Grande do Sul, Santa Catarina, Paraná, São Paulo, Minas Gerais, Centro-Oeste, Nordeste e Norte. Apenas alguns números foram produzidos pelos membros do Conselho Editorial. De modo geral, as regiões se revezavam na produção dos vários números, escolhiam o tema e seu coordenador. Esta organização teve o mérito de promover e provocar a produção de textos pelas diferentes regiões do país. Por outro lado, apresentou problemas como atrasos na publicação da revista, em razão das dificuldades de comunicação entre o coordenador e seus colaboradores e entre o coordenador local e a direção da revista em Petrópolis.

A organização geral da revista Estudos Bíblicos era acompanhada pelo Conselho Editorial. Os artigos de cada número eram lidos por um dos membros do Conselho, que sugeria eventuais correções ao texto. A responsabilidade primeira sobre o conteúdo do artigo cabia ao seu autor(a) e ao coordenador(a) regional do respectivo número. Os membros leitores do Conselho zelavam, também, pelo conteúdo dos artigos, sua orientação ecumênica e interesse pastoral. O conteúdo de cada número, de modo geral, tem sido temático, sem pretensão de esgotar o assunto. A partir do vol. 29, n. 113, janeiro/março 2012, a revista incluiu um Conselho Científico que, junto com o Conselho Editorial, se responsabilizava pela leitura crítica dos artigos a serem publicados. Em 2013, vol. 30, a revista ganhou novo layout: numeração de páginas continuada para os quatro fascículos, com novo cabeçalho e novo rodapé. Na página ímpar do cabeçalho, à direita consta o título do artigo e à esquerda o número da página. Na página par, à esquerda consta o número da página e à direita o nome do articulista. No rodapé da página constam os dados bibliográficos do artigo, à esquerda da página par e à direita da página ímpar. Exemplo: Estudos bíblicos, vol. 30, n. 117, p. 21-32, jan/mar 2013.

Nos primeiros anos, além dos estudos de caráter mais exegético-pastoral, a revista incluiu, uma vez ou outra, algum artigo de comunicação de experiências concretas no campo da pastoral bíblica. Aos poucos este aspecto foi sendo relegado. Outras publicações de caráter bíblico-pastoral surgiram com tais conteúdos, como as do CEBI (Centro de Estudos Bíblicos), suprindo muito bem tal necessidade.

7 O primeiro Conselho Editorial, chamado então "Conselho de Redação" representado por Gilberto Gorgulho, Carlos Mesters, Ludovico Garmus, Ana Flora Anderson, Milton Schwantes e José Comblin. 


\section{Perspectivas}

A revista Estudos Bíblicos sempre procurou manter um caráter ecumênico, não confessional, aberto também ao diálogo inter-religioso, especialmente com a tradição judaica, raiz comum de todas as Igrejas cristãs. Os coordenadores de cada região eram sempre lembrados a manter esta perspectiva ecumênica e inclusiva ao acolher os colaboradores de seu número.

O desejo dos idealizadores e colaboradores era aprimorar o estudo da Bíblia numa perspectiva libertadora, sem descuidar do aspecto científico. Estudos Bíblicos tinha como principais destinatários todos os interessados num conhecimento mais aprofundado da Bíblia, estudantes de teologia ou professores de Sagrada Escritura, pastores, sacerdotes ou agentes de pastoral de nossas comunidades.

A revista Estudos Bíblicos nasceu de uma iniciativa de exegetas e estudiosos da Bíblia. Desde o início, recebeu o apoio de professores da Faculdade de Teologia do Instituto Teológica Franciscano de Petrópolis (ITF) e foi produzida e comercializada pela Editora Vozes. À medida que foram sendo criadas novas revistas em Faculdades de Teologia e Universidades cresceu também a exigência de os respectivos professores publicarem na revista de sua Faculdade de Teologia ou Ciências da Religião. Com isso foi diminuindo também o interesse em publicar artigos na revista Estudos Bíblicos. O ITF já se comprometeu em buscar a qualificação A ou B para duas revistas fundadas pelos professores de Teologia com apoio da Vozes, que são a REB e Grande Sinal (Revista de espiritualidade). Não tem condições de assumir o mesmo compromisso com Estudos Bíblicos. Por isso procurou-se uma Universidade que tivesse interesse e condições de continuar mantendo viva nossa querida revista Estudos Bíblicos.

Como Editor responsável da revista senti um conflito cada vez mais visível entre o aspecto pastoral, pensado na origem, e as pressões sempre maiores por parte do MEC e das exigências acadêmicas dos colaboradores.

Apesar dos tropeços, em 2019, a revista Estudos Bíblicos chega ao volume 36, n. 142, em sua forma impressa. A partir do vol. 37, n. 143, 2020, passará a ser editada em forma eletrônica pela $\mathrm{ABIB}$, que assume o compromisso de dar continuidade à Revista Estudos Bíblicos. Com certeza, a nova direção da Revista Estudos Bíblicos encontrará um equilíbrio entre as exigências acadêmicas e o interesse pastoral buscado na origem.

Desejamos que a revista, em sua nova forma, continue animando o estudo da Sagrada Escritura e produzindo dignos frutos da Palavra de Deus para as Igrejas em nosso país.

\section{Referências}

BOFF, Leonardo; GARMUS, Ludovico. Editorial. Estudos Bíblicos, Petrópolis, n. 1, p. 5-6, 1984.

COMBLIN, José. Introdução geral ao comentário bíblico: Leitura da Bíblia na perspectiva dos pobres. Petrópolis: Vozes, 1985.

CORREIA JÚNIOR, João Luiz; OLIVA, José Raimundo (Orgs.). A esperança de um mundo novo: Estudos bíblicos em memória do profeta José Comblin. Estudos Bíblicos, Petrópolis, v. 30, n. 119, jul./set. 2014.

FERREIRA, Joel Antônio (Org.). Textos bíblicos, frutos de experiências transformadoras e a memória de Milton Schwantes. Estudos Bíblicos, Petrópolis, v. 29, n. 114, abr./jun. 2012, 
GARMUS, Ludovico. Estudos Bíblicos - 1984 a 2006. In: REIMER, H.; SILVA, V. (Org.). Libertação - Liberdade - Novos olhares. Goiânia: UCG; São Leopoldo: Oikos, 2008. p. 189-193.

. Estudos Bíblicos - 1984 a 2008. Estudos Bíblicos, Petrópolis, n. 100, p. 9-19, 2008.

GIRALDI, Luiz Antonio. A Bíblia no Brasil de hoje: como a Bíblia se tornou o livro mais lido no país. Barueri: SBB, 2018.

SILVA, Airton José da. Notas sobre alguns aspectos da leitura da Bíblia no Brasil hoje. Revista Eclesiástica Brasileira, Petrópolis, v. 50, p. 117-137, 1990.

SIQUEIRA, Tércio Machado; FRIZZO, Antonio Carlos (Orgs.). Leitura popular da Bíblia: Textos em homenagem a Gilberto Gorgulho. Estudos Bíblicos, Petrópolis, v. 31, n. 123, jul./set. 2014. 